\title{
O ANONYMOUS NAS JORNADAS DE JUNHO: QUESTÕES SOBRE AUTORIA NO FACEBOOK
}

\author{
PAULO NOBORU DE PAULA KAWANISHI ${ }^{1}$
}

pkawanishi@hotmail.com.br

\begin{abstract}
RESUMO. As manifestações de junho de 2013 marcaram tanto o país quanto seus cidadãos. No mesmo período, uma página no Facebook chamada de "Anonymous Brasil" ganhou uma grande quantidade de seguidores. Sendo assim, questionamos sua legitimidade para ocupar uma posição de legitimidade, o que nos levou a pesquisar sobre a autoria dos discursos que emergiam nos dizeres da página. Baseando-nos na definição do autor foucaultiana como uma função discursiva, procuramos compreender como a função se deu em um ambiente em que o anonimato predomina.

Palavras-chave: autoria; discurso; identidade; tecnologias de informação e comunicação.
\end{abstract}

\begin{abstract}
The 2013 july rallies have marked the country as much as the citizens. Simultaneously a Facebook page called "Anonymous Brasil" received a respectable amount of new followers. Therefore we inquired if the page had legitimacy to occupy such position, what lead us to research about the discourses' authorship found within the page. Based on the Foucaultian perspective of the author as a function, we ponder whether there is an author or not within the context of anonymity.
\end{abstract}

Keywords: authorship; discourse; identity; information and communication technology.

\section{Introdução}

Há alguns anos, a expressão "não é apenas por vinte centavos" foi apenas o início de um grande acontecimento que tomou todo o país. No mês de junho de 2013, milhares de brasileiros foram às ruas, invadiram prédios e ocuparam praças públicas, promovendo manifestações em suas cidades. Tanto as redes sociais digitais quanto os canais de notícia da televisão foram tomados por imagens das grandes avenidas do país. Ao mesmo tempo, havia a dúvida dos motivos que levaram tantas pessoas (vizinhos, amigos, parentes, por exemplo) às ruas para gritar por um país melhor.

O momento que posteriormente foi nomeado como as Jornadas de Junho foi constituído por práticas específicas. Entre elas, estava a negação de qualquer vínculo das manifestações com algum partido político e a descentralização dos grupos. Os manifestantes procuraram evitar que suas ações fossem relacionadas com políticos, partindo do argumento de que estes já não eram confiáveis como representantes do povo. Logo, eles não tinham o direito de querer significar a luta que ali começava. Ao mesmo

\footnotetext{
${ }^{1}$ Mestre em Linguística Aplicada pela Universidade Estadual de Campinas (UNICAMP).
} 
tempo, não era possível estabelecer uma liderança dentro da grande multidão. As passeatas aconteciam sem um propósito objetivo e cada manifestante parecia buscar pontos diferentes (KAWANISHI, 2016). Estas duas características acabavam deixadas de lado, dentro das redes sociais digitais, quando mais de um milhão de usuários passaram a seguir e a compartilhar os dizeres de uma página específica: a Anonymous Brasil.

A página ganhou espaço durante as manifestações, pois compartilhava fotos tiradas por manifestantes enquanto os atos aconteciam. No entanto, a relação dos seguidores com ela não se dava na dimensão de um consumidor e de um produtor de conteúdo. Esses passaram a consultar a página, deixando suas dúvidas àqueles que a gerenciava. $\mathrm{O}$ espaço da página se tornou um ponto de encontro, um lugar em que os seguidores desenharam uma narrativa sobre o que acontecia. Os usuários pareciam seguir a página dentro da rede social digital e fora dela, nas grandes avenidas do país.

O Anonymous já era conhecido como o nome de um coletivo de hackerativistas que tinha, como principal característica, o anonimato e a descentralização de suas ações, não sendo possível encontrar um líder ou um dono da ideia por trás do Anonymous. Dentro da própria página, em momento algum, os administradores foram nomeados e tomaram a liderança das ações. Toda a dinâmica estabelecida em torno da página motivou nossa dissertação de mestrado, levando-nos a questionar se haveria algo ou alguém, na página Anonymous Brasil, que estaria exercendo a função de autor do discurso, como Foucault (1970 [2011], 1969 [2006]) definiu. Assim, buscamos compreender como os dizeres compartilhados pela página eram legitimados.

Este artigo tem o objetivo de apresentar uma das estratégias utilizadas pelos usuários para constituir o Anonymous como um autor legítimo para que significasse e fosse responsabilizado pelos discursos que emergiam da página. Em outro momento (KAWANISHI, 2017), trabalhamos o papel das tecnologias de informação e comunicação e das narrativas transmídias no processo de construção de representações do Anonymous. Agora, propomos discutir os dizeres que evocaram memórias como meio de legitimar o Anonymous como sendo portador da verdade. Esta construção é baseada em memórias que se entrelaçam a partir de um significante em comum e estabelecem uma malha narrativa consistente. Selecionamos, então, comentários deixados por usuários, durante as manifestações, nas postagens feitas pela página como excertos de análises. Estas se basearam em um olhar discursivo-desconstrutivista (CORACINI, 2007; KAWANISHI, 2016), constituído tanto pelo conceito de discurso de Foucault (1970 [2011]) quanto pelo de desconstrução de Derrida (1978 [2009]). O artigo foi estruturado de maneira que apresente, antes das análises, as condições de produção dos dizeres e o conceito de autor. Nestas, discorreremos sobre a origem do Anonymous, sobre as redes sociais digitais e os papéis que tiveram em outras grandes manifestações nos anos que antecederam as Jornadas de Junho.

\section{Condições de produção}

As Jornadas de Junho poderiam, talvez, ter acontecido sem a presença do Anonymous Brasil nas redes sociais digitais, mas é inegável que os atos não teriam alcançado as proporções que vimos sem as tecnologias de informação e de comunicação 
(doravante TIC). Os primeiros atos foram organizados por sites e por aplicativos de conversa, assim como as redes sociais digitais facilitaram o compartilhamento de informações, como as ações dos policiais durante os protestos. Podemos apontar a origem dessa "força" das tecnologias digitais em seu funcionamento em rede.

Quando a Internet ainda era um projeto militar, já havia o objetivo de estabelecer comunicações com pessoas distantes, aumentando a velocidade com que as informações eram espalhadas. Duvidamos, porém, que imaginavam a potência deste tipo de comunicação nas mãos de milhares de pessoas. Várias manifestações, antes das Jornadas de Junho, foram potencializadas pela Internet, como o Occupy Wallstreet e a Primavera Árabe. Castells (2013) aponta que a magnitude destes eventos não era esperada. Eles simplesmente aconteceram, mas começaram

nas redes sociais da internet, já que estas são espaços de autonomia, muito além do controle de governos e empresas - que, ao longo da história, haviam monopolizado os canais de comunicação como alicerces de seu poder. Compartilhando dores e esperanças no livre espaço público da internet, conectando-se entre si e concebendo projetos a partir de múltiplas fontes do ser, indivíduos formaram redes, a despeito de suas opiniões pessoas ou filiações organizacionais. Uniram-se. (CASTELLS, 2013, p. 7-8)

Além de se unirem, os usuários conseguiam estabelecer narrativas que nem o governo nem a mídia tradicional conseguiram controlar. No caso das Jornadas de Junho, as informações sobre os atos de violência da polícia, durante os protestos, eram difíceis de serem censuradas individualmente pela facilidade de compartilhamento. Algumas das postagens da página Anonymous Brasil continham mais de três mil comentários e quatrocentos compartilhamentos (KAWANISHI, 2016), o que demonstra o alto índice de dispersão das informações. Em alguns momentos, páginas dentro do Facebook, por exemplo, foram fechadas pela própria empresa, o que foi irrelevante, pois não conseguiram calar os usuários.

É no modo de como as redes de narrativa sobre as Jornadas se formaram que estava a sua força. Podemos distinguir três tipos básicos de redes: a centralizada, a distribuída e a descentralizada. A primeira é uma estrutura sustentada por um único nó que liga todos a todos, havendo apenas este intermediário. A rede centralizada é extremamente frágil por depender de apenas um nó para manter os outros elementos constituintes conectados. Uma vez que este nó for prejudicado, toda a rede é desmanchada. A segunda rede se baseia na ideia de que não existem nós centrais, todos estão conectados uns com os outros. Pode-se afirmar que a rede distribuída dificilmente seria desestruturada, mas a informações demoraria muito para chegar de um ponto da rede a outro, tornando-se uma rede ineficaz. A terceira rede se baseia na dinâmica entre grandes e pequenos nós. Ao contrário da primeira, ela não é estruturada a partir de apenas um grande nó, mas de vários, chamados de hubs. Estes são os nós com o maior número de conexões e são o caminho mais curto para a informação transitar pela rede. É exatamente a rede descentralizada que traz as vantagens das duas primeiras que foi formada durante as manifestações.

Algumas páginas dentro das redes sociais digitais ou sites de grande alcance exerceram a função de hub, tendo várias pessoas acessando o seu conteúdo, o mesmo 
caso da página Anonymous Brasil. Por mais que uma página fosse fechada pelo serviço que a hospedava, outra iria tomar seu lugar como hub, pois os usuários iriam se deslocar e as informações continuariam a transitar. Tal organização impediu que governos, como o brasileiro durante as Jornadas, acabasse com a comunicação e transmissão de informações. Enquanto sites eram fechados, outros nasciam. Enquanto eventos eram frustrados, outros acabaram organizados.

Compreender como as redes se estabelecem e se estruturam nos ajuda explica um dos pontos que colaboraram para a constituição inicial da página Anonymous Brasil como um lugar que continha informações importantes: o número de conexões. Uma vez que a página se tornou um hub (BARABÁSI, 2002), ela passa a ter um certo grau de legitimidade perante os usuários. No entanto, apenas seu status de hub não encerra nosso questionamento sobre a autoria.

A história por trás do que chamam de "Anonymous" pode servir como um dos outros elementos que dava legitimidade aos dizeres da página. Visto por alguns como um coletivo ou como um grupo de hackers, o Anonymous é uma figura que chamou muita atenção nos últimos anos.

Estudiosos do coletivo Anonymous, como Coleman (2014) e Olson (2012), apontam o site "4chan" como o lugar de origem ou, pelo menos, onde começaram a ser organizadas as suas possíveis primeiras ações. Um dos grandes atrativos do 4chan era a possibilidade de interagir sem precisar de um cadastro. Qualquer pessoa poderia deixar comentários nos tópicos e a única informação que seria exibida era a palavra "anonymous" em cima. O que alguns usuários do fórum explicaram (WE ARE LEGION, 2012) é que, com a grande quantidade de postagens em anonimato, parecia que, na verdade, era uma única pessoa, cujo nome era "Anonymous", deixando todas aquelas postagens.

Os usuários do 4chan construíram uma representação de como seria o Anonymous (negro e de terno) e passaram a interagir nos mais diversos ambientes da Internet. Conhecidos por um discurso ácido e provocativo (muitas vezes ofensivo), os membros desse grupo entravam em jogos on-line com vários personagens iguais (todos negros e de terno), ocasionando um congestionamento nos servidores e impedindo que outros jogadores ficassem on-line. Em outros momentos, formavam suásticas com vários desses personagens.

Alguns usuários perceberam a força dos números e o potencial que o coletivo tinha para agir em outras esferas. Coleman (2014, p. 5) explica que "certos Anons começaram a usar o nome e a iconografia associada [ao Anonymous] - homens sem cabeça, vestindo um terno preto, em particular - para coordenar protestos políticos"2. Este é o ponto que marca o início das ações mais conhecidas dos grupos que agiam sob a bandeira do Anonymous, invadindo sistemas, organizando ataques de DDOS, divulgando dados que conseguiam obter em bancos de dados invadidos, além de praticarem ações fora do digital.

\footnotetext{
2 "certains Anons began using the anme and some associated iconography - headless men in black suits, in particular - to coordinate political protests".
} 
Assim que os grupos começam a agir, eles dão um rosto para o Anonymous: a máscara de Guy Fawkes. Esta parece ser o significante que liga a figura do grupo de hacker a um personagem conhecida pela cultura pop a partir da obra "V de Vingança". Esta, escrita por Allan Moore, foi inicialmente um quadrinho que, depois, ganhou uma versão cinematográfica que ajudou a popularizar a máscara que o personagem principal utiliza. A história é sobre um anti-herói que desafia um governo totalitário e tenta libertar o povo da alienação, enquanto procede com a sua vingança sobre aqueles que o usaram como cobaia em experiências.

O uso da máscara para simbolizar o Anonymous é um exemplo de uma de suas maiores características: não haver um controle sobre. Não existe um dono ou um grupo que comande todas as operações ou que diga o que o Anonymous é, pois, desde as primeiras manifestações, os sujeitos já diziam que qualquer um pode ser Anonymous. Não havia (e ainda não há) meio de controlar o uso do nome Anonymous e suas representações. $\mathrm{Na}$ verdade, para eles o nome não é propriedade de ninguém. Como explica Coleman (2014),

[n]enhum grupo ou indivíduo pode alegar posso legal do nome "Anonymous", muito menos de seus ícones e imagens. Naturalmente, isso ajudou o Anonymous a se espalhar pelo globo. Ele se tornou a quintessencial marca anti-marca, assumindo várias configurações e significados, assim como se tornou a face popular do descontentamento pelo globo. ${ }^{3}$ (COLEMAN, 2014, p. 16)

A pluralidade e o comportamento inesperado do Anonymous pode ser consequência dessa falta de regulação do uso do nome. Assim, encontra-se um ser que é constituído pelo caos de sua criação, levando-o a contradizer a si mesmo ou agir de maneira inesperada. Nunca se encontra o mesmo Anonymous.

Essa produção teve como consequência diversas células, grupos de pessoas que agem sob o nome ou seguem o Anonymous. No Brasil não foi diferente e, dentro da rede social digital Facebook, entre tantas outras, a página "Anonymous Brasil" foi criada. Inscrevendo-se na grande rede formada a partir do significante "Anonymous, a página se serve de toda a memória invocada por seu nome para que ganhe espaço e legitimidade para se lidar com questões políticas do país.

O Anonymous é um grande golem desenvolvido através da junção de representações, preenchendo suas lacunas, dando corpo ao rosto e ao nome. A seguir, apresentaremos o conceito de autor a partir de Foucault, questionando como um contexto em que o anonimato é constituinte pode haver um autor.

\footnotetext{
3 "[n]o single group or individual can claim legal ownership of the name "Anonymous" much less its icons and imagery. Naturally, this has helped Anonymous spread across the globe. It has now become the quintessential anti-brand brand, assuming various configurations and meaning, even as it has also become the popular face of unrest around the globe."
} 


\section{Sobre o autor e seu nome}

A chegada à marca de um milhão de seguidores da página Anonymous Brasil foi contra um consenso que existe desde que a Internet se tornou palco de interações entre as mais diversas pessoas: não dá para acreditar em tudo que é dito dentro dela. Ler qualquer texto cuja autoria é desconhecida, hoje em dia, é desconfiar de cada palavra e argumento, assim como ler um texto de determinado autor pode ser uma experiência diferente, dependendo de quem aquele ele é para o leitor. Esta figura que nos acompanha e tem tanta influência sempre chega até nós através de seu nome, mas, no caso do Anonymous, não existiria um nome em si. O que é, então, um autor? Uma pessoa? Ou um nome que não só nomeia, mas que "[é] mais do que uma indicação, um gesto, um dedo apontado para alguém" (FOUCAULT, 1969 [2006], p. 42)?

De acordo com Foucault (1969 [2006]), não se deve pensar no nome do autor como um nome próprio, pois a relação que o primeiro tem com a obra não é igual a que o último tem com a pessoa que nomeia. O nome próprio não sofrerá mudanças caso aquele que é nomeado mude. Já o nome do autor significa os discursos a partir da representação daquele que nomeia, tornando-se uma função dentro das práticas discursivas. O nome próprio estará sempre vinculado a uma pessoa real, enquanto o nome do autor se liga a uma representação. No caso da página, dependendo de quem ou o que exercia a função, seu nome significaria os dizeres de acordo com a representação que os seguidores teriam dele. Dificilmente, um milhão de pessoas tomaria os dizeres de uma página como verdade se não houvesse alguma legitimidade em seu autor.

Uma vez que Foucault (1970 [2011]) determina o autor como uma função discursiva, precisamos compreender de que maneira ela costuma ser exercida. De acordo com o filósofo (1969), o nome do autor

exerce relativamente aos discursos um certo papel: assegura uma função classificativa; um tal nome permite reagrupar um certo número de textos, delimitá-los, seleccioná-los, opô-los a outros textos. Além disso, o nome de autor faz com que os textos se relacionam entre si; [...]. (FOUCAULT, 1969 [2006], p. 44)

De acordo com Foucault (1970 [2011]), o novo não está no que é dito em si, mas nas condições que o permitem ser dito, tornando-se um acontecimento. É através do nome do autor que os discursos serão aproximados e terão uma "origem", camuflando o caráter de acontecimento de um discurso. Nem todos os discursos, em determinadas formações discursivas, exigiram o nome de um autor para lhe conceder legitimidade. $\mathrm{O}$ discurso científico é um exemplo que passou a ser sustentado pela lógica e por sua cientificidade, dispensando a necessidade de um autor.

O nome do autor passa a ter uma dimensão a mais no século XVIII, quando os discursos transgressores precisavam ser controlados e alguém seria responsabilizado por eles. Assim, a função parece exercer um controle externo ao discurso, pois as pessoas físicas ligadas aos nomes seriam punidas por governos, por exemplo, com o objetivo de encerrar a proliferação dos dizeres. Neste ponto não há como separar a pessoa física a quem o nome do autor pode remeter. A responsabilização de uma pessoa física foi um dos caminhos que a polícia brasileira tentou percorrer durante as Jornadas com o intuito de acabar com a influência da página Anonymous Brasil. 
O anonimato é um problema para a questão da autoria de duas maneiras: não existe um nome que ocupe a posição de nome do autor e não existe como relacionar a autoria dos dizeres a qualquer pessoa, suprimindo qualquer tentativa de censura. Algo ou alguém exercia a função de autor ou, provavelmente, as pessoas não teriam tomado como verdade os dizeres da página. A dificuldade de censurar os dizeres, resultante do anonimato, era uma vantagem. Tudo o que faltava era, então, de algum nome que significasse os atos do modo que os seguidores desejavam. Sendo assim, eles deslocaram o anonimato e o transformaram em uma entidade com nome: o Anonymous. A partir de suas narrativas, os seguidores deram sustentação a quem este seria, constituindo-o como um nome legítimo para exercer a função aqui discutida. $\mathrm{Na}$ próxima seção, apresentaremos dois excertos que, a partir da construção de representações do Anonymous como um ser que sabe a verdade e da invocação de memórias, participaram do processo de dar vida a esse golem digital (KAWANISHI, 2017).

\section{Resultado de análise dos dizeres sobre o Anonymous}

Os dois excertos que serão apresentados são representativos do tipo de prática que se estabeleceu a partir das narrativas construídas dentro da seção de comentários da página Anonymous Brasil pelos próprios seguidores. Durante todo o período das manifestações, nenhum suposto membro "oficial" do Anonymous tentou ocupar uma posição de legitimidade entre os seguidores e é muito improvável que conseguisse, caso tentasse. Dos comentários, representações sobre o Anonymous emergiam, constituindoo como um ser com um nome próprio e que teria contato ou possuiria a verdade. Neste momento, tanto a memória sobre as ações de hackerativismo dos grupos Anoymous e da obra V de Vingança são entrelaçadas para construir o Anonymous como o nome de autor legítimo.

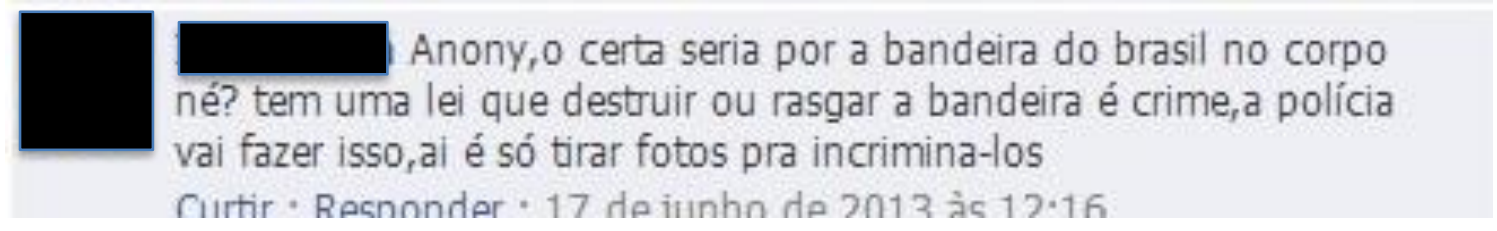

Excerto 1.

O primeiro excerto é o comentário de um seguidor que parece procurar confirmar duas verdades, sendo a primeira sobre se os manifestantes devem ou não cobrir seus corpos com a bandeira do Brasil e a segunda sobre a existência de uma lei que definiria, como crime, o ato de destruir uma bandeira do Brasil. Vários casos de agressão policial foram reportados durante as manifestações, desde agressões verbais ao uso de balas de borracha contra os manifestantes. Inicialmente, poderíamos tomar a questão levantada pelo seguidor como uma estratégia de resistência ao exercício de poder. No entanto, ao mesmo tempo, haveria a ação de incriminar, propositalmente, um policial que, tirando a farda, ainda era uma pessoa. A linha entre o certo e o errado mostrava-se turva para os manifestantes. 
O seguidor busca, então, em seu interlocutor, no caso, o "Anony" e não a página em si (Anoymous Brasil) a confirmação sobre as suas ações ("o [sic] certa seria por a bandeira..."). Procurar por este tipo de informação, traça a representação de que o Anonymous teria a legitimidade para confirmar o que é certo ou errado. É importante salientar que, durante as manifestações, como já foi mencionado, não haviam representantes da verdade sobre o que acontecia, uma vez que muitos acabavam silenciados pelas próprias massas das ruas, como alguns políticos. $\mathrm{O}$ usuário desloca a responsabilidade de apontar a linha entre o certo e o errado para o Anonymous a partir da pressuposição de que este detém a verdade, sendo que esta "é o que permite excluir; separar o que está perigosamente misturado; distribuir devidamente o interior e o exterior; traçar os limites entre o que é puro e impuro" (FOUCAULT, 1971 [2014], p. 168).

O efeito de sentido de responsabilização do Anonymous sobre os discursos de verdade se dá no movimento de confirmação do usuário a partir da partícula, pinçada na materialidade linguística. A partícula "né" ("o certo seria por a bandeira do brasil no corpo né?") produz o efeito de sentido de uma pergunta retórica, estratégia retórica que deslocar a responsabilidade para o interlocutor de apenas confirmar a verdade que já tenho. Podemos considerar que seguidor já sabia a verdade e como iria agir, uma vez que, ao descrever a lei e os processos que sucederiam à execução do plano, percebemos o uso do verbo ser no presente do indicativo ("rasgar a bandeira é crime", "ai é só tirar fotos" e "vai fazer isso"), apontando para um grau de certeza. Seus dizeres, além de construir a representação do Anonymous que sabe a verdade, também o torna seu cúmplice.

A aproximação da figura do Anonymous com a verdade concede à entidade uma posição de legitimidade. Quando Foucault (1971 [2014]) apresenta a história da verdade, como foi se transformando, ele aponta que ela tem uma relação direta com a lei, com o que é puro, características constituintes de seu possuidor. De acordo com o autor, na Grécia antiga, tinha-se

[o] [nómos] $]^{4}$ como princípio de distribuição, como princípio da justa repartição, é forçosamente inacessível ao impuro. [...] Inversamente, a pureza é condição para se ter acesso à lei: para ver a ordem das coisas e para poder proferir o [nómos]. Esse lugar mediano que, como vimos, é o lugar fictício em que se coloca o legislador, como Sólon, esse lugar mediano apenas quem for puro pode ocupar. (1971 [2014], p. 169)

O comentário do seguidor colabora na construção da representação do Anonymous como aquele que sabe a verdade, sustentando a sua legitimidade. Sem esta, ele não serviria como ponto de convergência e de significação de dizeres durante as manifestações, o que seria o papel do autor foucaultiano. O nome do autor, como Foucault (1970 [2011]) descreveu, precisa ocupar uma posição de legitimidade no discurso para dar coerência aos dizeres a ele vinculados que serão (re)estruturados, classificados, (re)agrupados, recortados.

Tentamos apresentar, neste primeiro excerto, na materialidade linguística, que havia a construção de uma representação do Anonymous como aquele que sabe a verdade e, logo, poderia exercer a função autor. Vale ressaltar, novamente, que não se trata da página ou dos grupos intitulados ou supostamente ligados aos Anonymous, mas, sim, uma

\footnotetext{
${ }^{4}$ Colocamos a tradução pela impossibilidade de digitar os caracteres gregos.
} 
entidade, um construto teórico que só passa a ter consistência a partir das narrativas feitas pelos seguidores. No próximo excerto, esperamos deixar claro que parte da legitimidade suposta do Anonymous vem de memórias que o constituem.

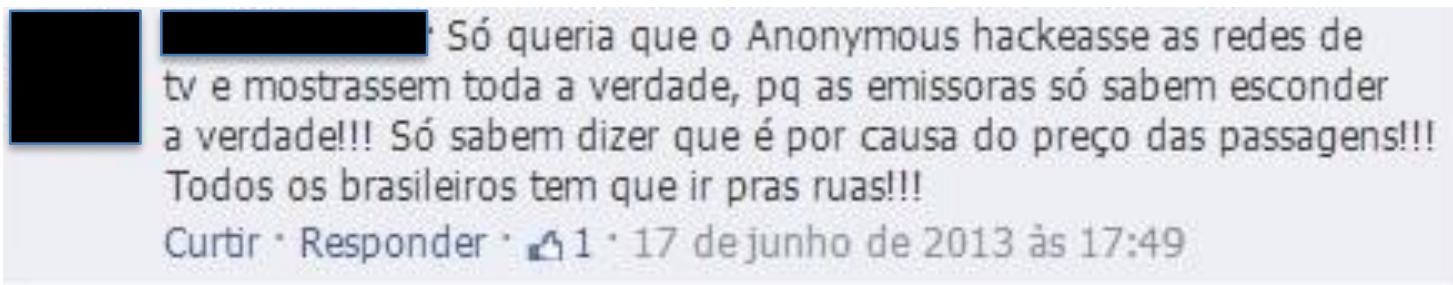

\section{Excerto 2.}

O segundo excerto se trata de um seguidor que expõe um desejo: de acordo com ele, o Anonymous poderia mostrar a verdade escondida pela mídia, uma das instituições deslegitimadas durante as manifestações. Há, assim como no primeiro excerto, a construção de uma representação sobre o Anonymous, mas que, dessa vez, é sustentada por memórias invocadas nos dizeres do seguidor.

Primeiro, é importante apontar que o seguidor se dirige ao Anonymous e não à página, assim como no excerto 1 . O uso do artigo definido ("o") o constitui como um ser específico. Contudo, é possível supor que os próprios usuários não entendem, não conseguem racionalizar, ainda, o que o Anonymous seria, uma vez que, no dizer do seguidor, a entidade transita entre o singular e o plural, como aponta o artigo e a desinência do verbo "mostrar". Como o Anonymous é construído de maneira diferente por cada seguidor, ele sempre será um e vários ao mesmo tempo.

O Anonymous é descrito como aquele que pode mostrar a verdade através da invasão de sistemas de computador das emissoras de televisão. As mídias tradicionais eram questionadas, durante as manifestações, por supostamente não apresentarem os fatos. Elas estariam manipulando informações para diminuir a magnitude dos atos. É exatamente no imaginário sobre as habilidades do Anonymous que duas memórias são invocadas.

A memória nada mais é do que uma construção baseada em uma seleção: para que algo seja guardado, arquivado, algo precisa ser esquecido. Sendo assim, a memória está sempre sendo transformada. Toda vez que é invocada, a memória se (re)apresenta. Como Andrade (2011) explica,

[a] memória seria, então, um conjunto de fragmentos desordenados, descontínuos, recalcados, diluídos, "esquecidos" ou inconsciente, que, num determinado momento, um "eu" se põe a "lembrar" e a organizar na linguagem, por intermédio de uma narrativa, dando um sentido para os pedaços que afloram os discursos, construindo, enfim, uma história, de certa forma una e com um final [...]. (ANDRADE, 2011, p. 84)

O usuário ordena, então, fragmentos de uma narrativa anterior, sobre momentos em que, como mencionado anteriormente, muitos grupos agiram em grandes manifestações sob o nome do Anonymous. Eles invadiram servidores e roubaram 
informações para depois expô-las publicamente, assim como, durante as manifestações, modificavam sites como um gesto simbólico que se equivaleria à ocupação de praças públicas. Ao supor que o Anonymous saberia como hacker um sistema ("...hackeasse as redes de tv..."), o usuário invoca a memória do Anonymous como hackerativista e o constitui com o discurso hacker.

O movimento hacker teve seu início narrado pelo jornalista Levy que conseguiu delinear uma ética entre os membros dos grupos hackers do Instituto de Tecnologia de Massachusetts (MIT). Obedecendo um sistema meritocrático, estes sujeitos acreditavam no livre acesso à informação, o que motivava os seus estudos sobre os sistemas e como utilizá-los para resistir às restrições de seus criadores. A desconfiança das grandes empresas e de instituições levou os hackers a estabeleceram práticas de resistência à monopolização da informação por parte desses (LEVY, 1994).

Entre as várias ramificações que o movimento hacker teve, todas sustentam a questão do livre acesso à informação. Desde os grupos que advogam pelos softwares livres até os underground hackers (COLEMAN, 2008), a informação, logo, a verdade precisa estar disponível para todos. Os hackers usariam de meios legais ou ilegais para conquistar o que veem como um direito. Sendo assim, o Anonymous, constituído por uma memória que o liga a ações hackers, teria as ferramentas, a habilidade para acessar a verdade que a mídia esconde.

Ao mesmo tempo que invoca o passado hacker, o seguidor também retoma uma memória ligada a um significante que constitui o Anonymous. Muitos dos manifestantes, durante as Jornadas, utilizaram uma máscara originária da obra V de Vingança que foi adotada pelos primeiros grupos Anonymous como a face deste. A máscara seria baseada no rosto de um revolucionário inglês, Guy Fawkes, que haveria tentado plantar explosivos sob o parlamento inglês, servindo como um significante que conecta o Anonymous à obra e aos seus discursos.

A ideia de invasão por trás da ação hacker, assim como o alvo desta ("redes de tv"), remontam a uma passagem da obra V de Vingança, em que o personagem principal invade a sede da única rede de televisão de Londres, sustentada por um partido totalitário, e que costuma manipular informações. O objetivo da personagem é transmitir um pronunciamento seu para toda a Inglaterra, em que diz a "verdade" para os cidadãos e os convida para uma manifestação contra o governo.

A personagem $\mathrm{V}$ é constituída por um discurso anárquico e revolucionário. Ela busca expor a verdade como um meio de se vingar dos abusos de um poder ludibriante que foi capaz de fazer mal ao seu próprio povo como meio de legitimar sua posição. Este não seria, também, o papel do Anonymous para o seguidor? Tanto o Anonymous quanto a personagem $\mathrm{V}$ dividem o mesmo rosto, a máscara de Guy Fawkes, aproximando o primeiro do segundo, a ponto de ser impossível distinguir ambos.

A narrativa apresenta um Anonymous revolucionário e transgressor que é ainda capaz de alcançar a verdade. A recorrência de representações que mantêm uma relação entre o Anonymous e a verdade deram legitimidade para que este exercesse a função autor, servindo como um porta-voz da verdade sobre as Jornadas de Junho que eram, realmente, construídas pelos próprios seguidores. 


\section{Considerações finais}

Neste artigo, nós buscamos apresentar uma das principais questões que foi desenvolvida em nossa pesquisa de mestrado. A pergunta inicial, de nossa pesquisa, era sobre a questão da autoria foucaultiana e o suposto anonimato, ou seja, ausência de um nome de autor dentro da página Anonymous Brasil. Após nossas análises, pudemos reconhecer recorrências, na materialidade linguística, como as aqui apresentadas, de narrativas dos seguidores sobre o Anonymous.

A ideia por trás do Anonymous e a própria figura, assim como explicamos, começaram de uma maneira que impossibilitou qualquer tentativa de estabelecer uma posse sobre eles. Uma vez que qualquer um pode ser ou falar sobre o Anonymous, não há uma verdade absoluta sobre ele. Existem apenas as verdades daqueles que se envolvem com o significante. Acreditamos que pudemos apresentar, brevemente, alguns exemplos de como a entidade Anonymous foi construída, no caso das Jornadas de Junho, pelos próprios seguidores da página.

Os dois excertos escolhidos continham elementos que apontavam para um desejo dos seguidores sobre quem o Anonymous deveria ser. Servindo como um símbolo para os manifestantes, ele significaria as depredações, a violência e a luta como aspectos de uma manifestação pelo bem do povo. Afinal, em nenhuma das manifestações anteriores, em que o Anonymous esteve presente, ele estava contra os manifestantes. Ele legitima a luta contra a opressão. Assim, a palavra "anonymous" foi deslocada e passou a ser um substantivo próprio, o nome do autor.

A narrativa foi constituída por uma memória constituída pelas atividades hackerativistas de vários grupos, além da obra "V de Vingança". Tal memória possibilitou a construção de uma representação do "Anonymous" como portador da verdade, o que o legitimaria para exercer a função de autor, controlar e ser responsabilizado pelos discursos que emergiam durante as manifestações de junho. Assim, os cidadãos poderiam agir a partir de uma certeza confirmada por alguém em posição para isso.

Apesar de todo esse movimento na construção de um autor para exercer a função, o que marcaria algo novo dentro de seu funcionamento de acordo com o que Foucault (2006) havia trabalhado, há ainda o mesmo, o igual. Os sujeitos não conseguiram se desvencilhar da necessidade de um nome ou de lidar com uma autoria que poderia ser considerada em grupo. No fim, os seguidores produziram o "Anonymous" como eixo de coerência e depósito da verdade, evitando ter que lidar com todo o coletivo buscando exercer a função. Voltaram, mesmo em um contexto e momento tão propenso para ir além, à centralização, à individualização, à lógica de um nome coerente.

\section{Referências}

ANDRADE, E. Um arquivo vivo em construção. Em: CORACINI, M.J., GHIRALDELO, C.M. (Orgs.). Nas malhas do discurso - memória, imaginário e subjetivdade. Campinas: Pontes, 2011.

BARABÁSI, A. Linked. New York: Penguin Books, 2002. 
CASTELLS, M. Redes de indignação e esperança - movimentos sociais na era da internet. Rio de Janeiro: Zahar, 2013.

COLEMAN, G. Hacker, hoaxer, whistleblower, spy - the many faces of Anonymous. New York: Vero, 2014.

COLEMAN, G., GOLUB, A. Hacker practice - moral genres and the cultural articulation of liberalism. Antropological Theory, v. 8(3), 255-277, 2008.

CORACINI, M.J. A celebração do outro. Campinas: Mercado de Letras, 2007.

DERRIDA, J. Carta a um amigo japonês, 1987. Em: OTTONI, P. (Org.). Tradução - A prática da diferença. Campinas: Editora da Unicamp, 2009.

FOUCAULT, M. Aulas sobre a vontade de saber. São Paulo: Martins Fontes, 2014.

A ordem do discurso. São Paulo: Loyola, 2011.

O que é um autor? Lisboa: Nova Vega, 2006.

KAWANISHI, P. O golem digital: a narrativa transmídia como estratégia na construção de uma verdade. Domínios de Linguagem, UFU, v. 11, n. 3, 2017. Disponível em http://www.seer.ufu.br/index.php/dominiosdelinguagem/article/view/37288. Acesso em 9 out. 2017.

- Identidade e autoria no ciberespaço: os dizeres de um autor sem nome. Dissertação. Mestrado em Linguística Aplicada, Unicamp, 2016.

LEVY, S. Hackers: heroes of the computer revolution. New York: Dell Publishing, 1994.

OLSON, P. Nós Somos Anonymous. Barueri: Novo Século Editora, 2014.

We are Legion. The story of hackativists. Dir. B. Knappenberger. Luminant Media, 2012.

Artigo recebido em: maio de 2017.

Aprovado e revisado em: setembro de 2017.

Publicado em: novembro de 2017.

\section{Para citar este texto:}

KAWANISHI, Paulo Noboru de Paula. O Anonymous nas Jornadas de junho: questões sobre autoria no Facebook. Entremeios [Revista de Estudos do Discurso, on-line, www.entremeios.inf.br], Seção Temática [Linguagem e Tecnologia], Programa de PósGraduação em Ciências da Linguagem (PPGCL), Universidade do Vale do Sapucaí (UNIVÁS), Pouso Alegre (MG), vol. 15, p. 213-224, jul. - dez. 2017.

DOI: http://dx.doi.org/10.20337/ISSN2179-3514revistaENTREMEIOSvol15pagina213a224 